\title{
Cost Efficiency in Primary Care Contracting: A Stochastic Frontier Cost Function Approach
}

\author{
July 2003 \\ Jaume Puig-Junoy*, Vicente Ortún \\ Universitat Pompeu Fabra, Department of Economics and Business, Research Centre on Economics and \\ Health (CRES), Trias Fargas 25-27,34-08005 Barcelona, Spain
}

\begin{abstract}
The principal aim of this paper is to estimate a stochastic frontier cost function and an inefficiency effects model in the analysis of the primary health care services purchased by the public authority and supplied by 180 providers in 1996 in Catalonia. The evidence from our sample does not support the premise that contracting out has helped improve purchasing cost efficiency in primary care. Inefficient purchasing cost was observed in the component of this purchasing cost explicitly included in the contract between purchaser and provider. There are no observable incentives for the contractedout primary health care teams to minimise prescription costs, which are not explicitly included in the present contracting system.
\end{abstract}

Keywords: Primary health care; purchasing cost efficiency; frontier models.

JEL codes: H51, I18.

\footnotetext{
* Corresponding author. Fax: +34-93-542-17-46.

E-mail address: jaume.puig@upf.esdu (J. Puig-Junoy)
} 


\section{Introduction}

The introduction of competition among health care providers has been widespread in recent decades in publicly financed health systems throughout the world. Reforms designed to foster competition entail the assignment of the purchasing and production functions to two different types of organisations. According to this principle, public authorities are converted into purchasing-only bodies without any direct involvement in the actual production of health services. The logic behind these policies is to use price mechanisms rather than planning mechanisms to guide resource allocation. A key point in these so-called market-type reforms is cost efficiency of the contracting agency, that is, the attempt to minimise the cost of obtaining a desired level of quantity and quality of health services. However, cost efficiency of the purchasing agency has rarely been the object of empirical evaluations.

\subsection{Institutional context}

Primary health care represents around $30 \%$ of total public expenditure in Spain, including pharmaceutical costs. Nowadays it tends to be organised on a territorial basis (Basic Health Areas or Àrees Bàsiques de Salut, ABS's). Primary health care teams (PHCT's), consisting of general practitioners, nurses, paediatricians and other personnel, have been created since the reform in 1984 in an attempt to establish a more prevention-focused primary care service, increase consultation times, promote team working among professionals and eliminate ambulatory specialist care [1, 2]. PHCT's are functional units of medical and non-medical professionals who offer integrated health services to a geographical area known as a basic health area.

The Catalan health care system is no exception to the prevailing reforms; the separation of the purchasing and production functions was initiated in 1990 by the Catalan Parliament passing the Law on Health Care Organisation in Catalonia (Llei d'Ordenació Sanitària a Catalunya, LOSC). The Catalan Health Service (Servei Català de la Salut, SCS) is a public purchasing authority which does not manage any health services or employ any staff providing clinical health services. The SCS plays the role of a purchasing organisation contracting both public and private providers. 
In the past, the only primary health care provider in Catalonia was the Catalan Health Institute (Institut Català de la Salut, ICS). In recent years the Catalan health system has experienced the introduction of several forms of contracting primary health care from providers outside the ICS.

There are two main types of contracts between purchaser (SCS) and provider, and four types of primary care providers. One of these types of contract is associated with the three new types of providers (see below) and has come to replace former hierarchical relationships with new contractual relationships based mainly on a retrospective payment system. Contracted PHCT's are accountable for only 5\% of the overall budget, on the basis of their fulfilment of a given set of objectives [3]. These objectives are related to qualitative and quantitative results of drug prescription, and also to targets specified in the health plan (i.e., population aged 0-14 correctly vaccinated, population aged over 64 vaccinated against influenza, population included in the home care programme, etc.) [4]. The cost of pharmaceutical prescription is excluded from these contracts. Resource allocation to these providers previously managed by the integrated public authority is basically of a retrospective type.

The other type of contract between purchaser (SCS) and provider, the so-called programme-contracts, has been introduced into the relationship with those primary care providers which prior to 1990 were managed by the integrated (i.e., purchasing and providing) public authority. The price paid by the SCS to these ICS primary care providers is based on historical costs for the current inputs and a simple cost recovering mechanism for the cost of prescription drugs, which accounts for more than half of total expenditures.

Most of the primary care teams offering integrated health services to a basic health area are managed by the public authority, the ICS (88.7\% of those in existence in 1999); however, the public purchaser has encouraged the appearance of a number of new providers. These new primary care providers may be classified into three different types: (i) horizontally integrated providers, (ii) "mutuas", and (iii) professional cooperatives [5]. Horizontally integrated providers usually supply specialist and primary care and are managed by an organisation that was previously only managing a hospital. 
This has been the most prevalent form of organisation among the new providers. The so-called "mutuas" are very similar to some American health maintenance organisations (HMO's). The most recent organisational form for the new providers is that of the professional co-operatives, which are similar to the general practitioners that became fundholders in the United Kingdom.

\subsection{Objectives}

The object of this paper is to improve knowledge of cost efficiency in primary care contracting in the Catalan health system through two specific goals. The first is to obtain a measure of the cost efficiency of services that the purchasing agency is contracting from each provider. The second is to quantify the sources of cost inefficiency in purchasing primary care. In this context, cost efficiency is defined as the ability to buy a given level of quantity and quality of primary care services at the minimum price. Therefore, the public purchaser is inefficient if it does not minimise the price when buying a given level of services from a particular provider (output). Cost efficiency can be advocated as a suitable measure to compare ex-post performance of contracts arranged by the public purchaser to buy primary care services for a given population.

This study differs from previous work on efficiency in primary health care services in three ways. Firstly, it attempts to measure cost efficiency in contracting health care services, which is different from measuring efficiency in the production of health care services. Secondly, it estimates stochastic inefficiency scores, whereas the prevailing methods in the preceding literature on primary care efficiency measurement have been non-parametric and deterministic. Thirdly, it applies to primary health services the approach developed by Battese and Coelli [6], in which the inefficiency effects are modelled as an explicit function of a number of variables which are thought to influence the level of cost inefficiency in contracting primary care services. To our knowledge, this paper is the first primary health care study to estimate efficiency using the Battese and Coelli [6] model and also the first to explore the level and sources of cost inefficiency in contracting primary care services. 
Efficiency measures of the production of services provide information about the efficiency of the providers in the transformation of inputs into outputs. However, the topic of this paper is not provider efficiency but purchaser efficiency estimated at the level of each purchaser-provider contractual arrangement. These two measures of efficiency are independent and may differ greatly because they quantify different aspects of health care provision: a primary care provider may be cost efficient in producing a given level of output, but the purchasing agency may buy this output at a price above the competitive or the minimum observed price for the same output. The previous literature on efficiency measurement of health care has focused its attention only on provider efficiency.

The task of evaluating cost efficiency in contracting primary care from different providers (how close the purchasing decisions are to the "best-practice" frontier) is done by frontier analysis, applying stochastic and parametric techniques to each purchaserprovider contract. The advantage of frontier analysis is that it provides an overall, objectively determined, numerical efficiency value and ranking of contracts that is not otherwise available. The stochastic frontier approach allows observations to depart from the frontier due to both random error and inefficiency, whereas models using Data Envelopment Analysis (DEA) measure random error as part of inefficiency, that is, they confuse random error with inefficiency (any departure from the frontier is measured as inefficiency). In a survey of the literature in English and Spanish on the efficiency measurement of the production of primary care services [7] we identified 24 papers that applied frontier analysis. The non-parametric but deterministic DEA approach was the only method employed in 22 of the 24 papers. The only study that estimated both the stochastic and the non-parametric cost frontier to examine performance in providing primary health care was Giuffrida and Gravelle [8]. As has been observed in other studies, these authors confirmed that the correlation between the scores obtained using econometric and DEA-type methods is rather low.

The paper continues with the following structure. Section 2 outlines the stochastic frontier approach with the inefficiency effects model and the empirical specification of the cost function. Empirical results derived from this model are presented in Section 3, including the analysis of the efficiency scores and the estimates of the inefficiency function. The final section summarises and discusses the findings of this research. 


\section{Method}

\subsection{The stochastic cost frontier function}

Our method constructs a best-practice cost frontier from the data in the sample (i.e., we construct a cost frontier for the public purchasing agency, the SCS, and compare individual purchasing contracts with that frontier). Frontier approaches do not necessarily observe the true (unobserved) technological frontier, but rather the bestpractice reference technology. An observation is cost inefficient if it does not minimise its cost given its output. Efficiency scores of unity mean that the contract is on the frontier. Efficiency scores greater than unity mean that the contract is above the frontier: in this case, a further proportional decrease in cost is feasible, given output level and technology. We assume that in each contract the public purchaser attempts to minimise cost from a given set of outputs.

The cost of purchasing primary care services incurred by the purchasing agency is the total amount paid to a specific provider for the output sold to the public purchaser. The output is identified as the quantity and quality of primary care services provided to the population of a basic health area (ABS). The cost of purchasing primary care for this population area is defined as all the expenses incurred by the purchaser corresponding to primary care services provided to the targeted population, except capital costs. Thus, the concept of cost includes not only direct payments to the provider of primary care but also expenses directly derived from clinical decisions taken by this provider, most importantly those corresponding to drug consumption and laboratory and radiology services, which are paid directly to the provider of these specialised services.

One problem that arises with this measure of purchasing cost is that a large proportion of pharmaceutical cost corresponds to induced prescription by other professionals (in hospitals or private practices), which cost is for the most part beyond the responsibility of general practitioners. The Primary Health Care Study Group-Barcelona [9] found 
induced prescription in a sample of general practitioners in Barcelona to account for $46 \%$ of prescriptions.

Cost efficiency in primary care contracting is obtained when the cost of providing a given level of quantity and quality of primary care services to a specific population (the output contracted by the purchaser) is minimised. Thus, an efficient purchasing agency will buy a given output from a primary care provider incurring the minimum cost, given the underlying production technology in the provision of services.

Economic theory can easily predict that in the presence of a sufficient degree of purchaser and provider competition the price paid for a given output would tend to be that corresponding to the minimum cost of production, given the technology and the input prices. Consider primary care provider i contracting services with a public purchaser over period $t$, and employing $\mathrm{k}$ inputs $\mathrm{x} ?\left(\mathrm{x}_{1}, \ldots \mathrm{x}_{\mathrm{k}}\right)^{\mathrm{T}}$ available at fixed prices $\mathrm{w} ?\left(\mathrm{w}_{1}, \ldots \mathrm{w}_{\mathrm{k}}\right)^{\mathrm{T}}>0$ to produce $\mathrm{n}$ outputs $\mathrm{y} ?\left(\mathrm{y}_{1}, \ldots \mathrm{y}_{\mathrm{n}}\right)^{\mathrm{T}}$ representing primary health care services for a given population area (basic health area $i$, given that only one provider is contracted for each area). If the provider and the purchaser behave competitively, the purchasing cost function is represented by $\mathrm{C}\left(\mathrm{y}_{\mathrm{i}}, \mathrm{w}_{\mathrm{i}}\right)$, which represents the minimum cost of producing output y ( $\mathrm{n}$ primary care services provided to the population of area i) at input prices $\mathrm{w}$ under normal production conditions.

In practice, the actual cost of purchasing primary care services for the population in area i may differ from the efficient cost for several reasons. One reason is that the actual cost of purchasing certain services may be either higher or lower than the minimum cost as a result of favourable or unfavourable unsystematic influences (random shocks). Another important reason is that in the absence of competition between purchasers for public purchasing finance, as is the case in the Catalan health system, incentives for the public purchaser to behave cost efficiently are limited. In this case, market structure and regulatory constraints may prevent the minimisation of the cost of purchasing any given level of output, and the public authority may fail to achieve cost efficiency in purchasing services for population area $i$. In this case, the actual cost lies above the cost frontier (expected minimum level). 
We consider a cross-section data model for inefficiency effects in stochastic cost frontiers based on the Battese and Coelli [6] model. Our stochastic frontier cost model allows inefficiency effects to be a function of a set of explanatory variables, the parameters of which are estimated simultaneously with the stochastic frontier. The approach is stochastic and the observations may be off the frontier because they are inefficient or because of random shocks or measurement errors.

The cost of purchasing primary care services for population area $\mathrm{i}$ is represented by the stochastic frontier cost function, written as:

$$
\mathrm{C}_{\mathrm{i}}=\mathrm{C}\left(\mathrm{y}_{\mathrm{i}}, \mathrm{w}_{\mathrm{i}}\right)+\left(\mathrm{V}_{\mathrm{i}}+\mathrm{U}_{\mathrm{i}}\right)
$$

In equation (1), $V_{i}$ values are assumed to be independent and identically distributed random errors, which have normal distribution with mean zero and unknown variance $?^{2} \mathrm{v}$, and independent of $\mathrm{U}_{\mathrm{i}} \cdot \mathrm{U}_{\mathrm{i}}$ are non-negative unobservable random variables associated with cost inefficiency, which are assumed to be independently distributed as truncations at zero of the $\mathrm{N}\left(\mathrm{m}_{\mathrm{i}}, ?^{2}{ }_{\mathrm{U}}\right)$ distribution, $\mathrm{m}_{\mathrm{i}}$ being a vector of effects specific to population areas, with $\mathrm{m}_{\mathrm{i}}=\mathrm{z}_{\mathrm{i}}$ ?

In the cost inefficiency effects model the error term is composed of the following two components: cost inefficiency effect and statistical noise. The two error components represent two entirely different sources of random variation in cost levels that cannot be explained by output and input prices. The cost inefficiency effects, $U_{i}$, could be specified as:

$$
\mathrm{U}_{\mathrm{i}}=\mathrm{z}_{\mathrm{i}} ?+\mathrm{W}_{\mathrm{i}}
$$

In equation (2), $\mathrm{z}$ is a vector representing possible efficiency determinants, and ? is a vector of parameters to be estimated. $\mathrm{W}_{\mathrm{i}}$, the random variable, is defined by the truncation of the normal distribution with mean zero and variance $?^{2}$, such that the point of truncation is $-\mathrm{z}_{\mathrm{i}}$ ? 
Two-step procedures for estimating the determinants of cost efficiency, previously used in the parametric literature, suffer from a fundamental contradiction. The second stage involves the specification of a regression model for the predicted cost inefficiency effects, which contradicts the identical distribution assumption of the first stage. The Battese and Coelli [6] model overcomes this contradiction and allows the simultaneous estimation of the parameters of the stochastic frontier and the inefficiency model.

$U_{i}$ provides information on the level of cost inefficiency of contract $i$. The level of cost efficiency $\mathrm{CE}_{\mathrm{i}}$ may be calculated as the ratio of frontier minimum cost (on the cost frontier) to observed cost. This measure is bounded between zero and one. An estimated measure of cost efficiency in purchasing primary health care for population area $i$ in a given year may be obtained as:

$$
\mathrm{CE}_{\mathrm{i}}=\exp -\left(\mathrm{U}_{\mathrm{i}}\right)
$$

The unobservable quantity $\mathrm{U}$ may be obtained from its conditional expectation given the observable value of $\left(V_{i}+U_{i}\right)[10,11]$.

\subsection{Empirical specification}

2.2.1. Specification of the cost function model.- Data analysis in this paper is based on the estimation of the stochastic frontier cost model (equation 1) and the inefficiency function (equation 2). To render the model (equation 1) operational a Cobb-Douglas frontier cost function is chosen as the functional form.

To limit the restrictive properties imposed on the production process, a translog cost function was also tested against the restricted Cobb-Douglas functional form.

Data. - Our data consists of a cross section of observations on 180 Catalan primary health care teams (PHCT's) in Catalonia during 1996. PHCT's are the only provider of primary health care services in a given population area (basic health area, ABS). Consequently, our unit of analysis coincides with the contract for the rendering of primary care services by a health provider (PHCT) in a small area of covered population 
(ABS). These services are publicly financed and they are contracted by the SCS acting as the only buyer of services. Contracts may take several forms, but in general they are of the programme-contract type with a limited risk transfer, especially in the case of public providers (those belonging to the public group ICS). Contracts with new providers outside the previous integrated public authority involve a greater degree of risk assumption by the provider than in the case of public providers. However, risk transfer is very limited in all cases because all contracts exclude the cost of the pharmaceutical consumption and the cost of diagnostic tests (laboratory and radiology services).

The sources of the information are the following: (i) a survey by the Health Area of the SCS on the evaluation of primary care contracts in 1996 provided information on covered population, activity, health targets, quality and some environmental variables for each PHCT; (ii) detailed financial information from the SCS provided data about cost level and structure at PHCT contract level; and (iii) demographic and socioeconomic data for each population area was provided by the Catalan Statistical Institute. The sample is representative of the different types of PHCT's in terms of demographic composition, size, ownership, income, location and cost structure. PHCT's not considered in the study were excluded because data was not available or it was unreliable.

2.2.2. Variables in the cost function model.- The specification of the cost function in equation 4 requires the definition of three types of variables: the cost of purchasing primary care services for a population area $\left(C_{i}\right.$ in equation 1$)$, the quantity and quality of services provided (output; $\mathrm{y}_{\mathrm{ij}}$ in equation 1 ), and input prices ( $\mathrm{w}_{\mathrm{i}}$ in equation 1 ).

Purchasing cost (COST) for the SCS is measured by the observed payment to the primary care provider (PHCT) plus other health expenditures of the covered population, which are directly related to the clinical decisions of the PHCT. Other health expenditures are defined in this study as including three items: pharmaceutical expenditure, laboratory costs and radiology costs.

In the case of new providers, observed payment to the PHCT coincides with the direct financial flow to the provider, which theoretically reimburses labour and other current 
costs. In the case of public providers within the ICS group, given that financing is based mainly on the cost of the inputs, observed purchaser payment is measured as labour and other current costs of each PHCT. Pharmaceutical expenditure is measured as the cost of drugs prescribed by the physicians belonging to the PHCT and dispensed by a pharmacy. Drugs are valued at the 1996 retail price. The imputed costs of laboratory and radiology services are calculated using the number of derivations in each population area and the cost per service. Cost per service used in this study is defined as the 1996 regulated price to be used when the public sector is contracting out these services.

Detailed input prices are not available at the level of each PHCT. Pharmaceutical prices are regulated at the national level, which means that these prices are equal for all providers. An input price variable (PRICE) is defined in this study as the average ratio of expenditure on personnel and current services divided by the total number of personnel employed in each PHCT.

Empirical measurement of output in health care services is a controversial subject. In the evaluation of health care services it can rarely be accurately measured. The most common output measure employed in the literature is the number of visits or consultations with primary care professionals. Usually this is unavoidable as a result of the limited information available, but the number of visits is not an appropriate variable for measuring provider performance. A number of obvious problems appear when this is the only measure of output, for example: (i) there is no correlation between the number of visits, largely determined by the physician, and the quality of primary care (ii) in any given covered population, the number of recommended visits depends on population heterogeneity (age, social status, etc.); (iii) the contribution of intermediate outputs such as visits to health improvement depends on the effectiveness of these visits; etc.

Only three studies, of the 24 papers on primary health care efficiency measurement that we identified in the literature [7], did not use intermediate outputs as the only output measure. Salinas-Jiménez and Smith [12] addressed the quality problem using a theoretical model of primary care performance based on the assumption that certain quality indicators can act as proxies for outcome. These authors also highlighted the importance of some environmental factors, which affect efficiency level and are beyond 
the control of the provider. Giuffrida and Gravelle [8] employed a similar approach. Giuffrida [13] used a model of primary health care provision which includes the number of registered patients and various types of activity, such as the number of general practitioners (GPs) achieving a given objective of population coverage, as output measures. This author also introduced some quality and control variables into the model.

Output measurement in this study is based on the model of primary health care provision presented by Giuffrida [13]. PHCT's provide primary care services to the population covered in their population area (ABS) by means of general practitioners, paediatricians, dentists, practice nurses, social workers and other ancillary personnel. The final outcome is the improvement in the health status of the population served (i.e., quality adjusted life years). In the empirical approach we rely on intermediate output measures which are related to health improvement: services provided and quality of primary care. A total of 13 intermediate outputs are included in the frontier cost function (Table 1): covered population (3), activity (3), health targets (5), and quality of care (2).

In our study three types of measures of services provided are employed: covered population, activity, and health targets. First, the size and composition of the covered population: resident population in the ABS aged 0-14 (POP014), aged 15-64 (POP1564), and aged over 64 (POP65). Second, the activity of the PHCT measured as the number of visits and the continuity of the service: the number of general practitioner, paediatrician and dentist visits (MEDICVISITS), the number of nurse and social worker visits (NURSEVISITS), and the population covered which can receive care 24 hours a day (CONTINUOUS). Third and finally, the level of some specific health targets in the covered population: population aged 0-14 entered in the register of vaccinations and correctly vaccinated (CHILDVACCIN), population aged over 15 entered in the register of adult vaccinations and correctly vaccinated against tetanus (TETANUS), population aged over 64 vaccinated against influenza (INFLUENZA), population aged 0-14 included in the health programme for a healthy childhood (CHILDPROGRAM), and population included in the programme for home health care (HOMECARE). 
Quality of primary care is approximated by measuring two proxy quality variables defined according to the limitations of the available information: the number of affirmative answers to ten questions indicating PHCT quality as detailed in Table 1 (ITEMS), and the proportion of covered population aged over 65 that is included in the home health care programme (HOMECARE65).

The empirical specification of the Cobb-Douglas frontier cost function is as follows:

$\log \left(\mathrm{COST}_{\mathrm{i}}\right)=?_{0}+?_{1} \log \left(\right.$ PRICE $\left._{\mathrm{i}}\right)+?_{2} \log \left(\right.$ MEDICVISITS $\left._{\mathrm{i}}\right)+?_{3}$ $\log \left(\right.$ NURSEVISITS $\left._{\mathrm{i}}\right)+?_{4} \log \left(\right.$ CONTINUOUS $\left._{\mathrm{i}}\right)+?_{5} \log \left(\mathrm{POP} 014_{\mathrm{i}}\right)+?_{6} \log \left(\mathrm{POP} 1564_{\mathrm{i}}\right)$ $+?_{7} \log \left(\right.$ POP65 $\left._{\mathrm{i}}\right)+?_{8} \log \left(\right.$ CHILDVACCIN $\left._{\mathrm{i}}\right)+?_{9} \log \left(\right.$ TETANUS $\left._{\mathrm{i}}\right)+?_{10}$ $\log \left(\right.$ INFLUENZA $\left._{\mathrm{i}}\right)+?{ }_{11} \log \left(\right.$ CHILDPROGRAM $\left._{\mathrm{i}}\right)+?{ }_{12} \log \left(\mathrm{HOMECARE}_{\mathrm{i}}\right)+?_{13}$ $\log \left(\right.$ ITEMS $\left._{\mathrm{i}}\right)+?{ }_{14} \log \left(\right.$ HOMECARE65 $\left._{\mathrm{i}}\right)+\mathrm{V}_{\mathrm{i}}+\mathrm{U}_{\mathrm{i}}$

Where:

COST $=$ Purchasing cost in pesetas per PHCT including pharmaceutical, laboratory and radiology services,

PRICE = Average ratio of expenditure on personnel and current services, excluding pharmaceutical expenditure, divided by the total number of personnel employed in the PHCT,

MEDICVISITS $=$ Number of general practitioner, paediatrician and dentist visits,

NURSEVISITS $=$ Number of nurse and social worker visits,

CONTINUOUS $=$ Number of residents that can receive care 24 hours a day,

POP014 = Resident population aged 0-14,

POP1564 = Resident population aged 15-64,

POP65 = Resident population aged over 64,

CHILDVACCIN = Population aged 0-14 entered in the register of vaccinations and correctly vaccinated,

TETANUS $=$ Population aged over 15 entered in the register of adult vaccinations and correctly vaccinated against tetanus,

INFLUENZA = Population aged over 64 vaccinated against influenza,

CHILDPROGRAM = Population aged 0-14 included in the health programme for a healthy childhood, 
HOMECARE $=$ Population included in the home health care programme,

ITEMS = Number of affirmative answers to ten questions indicating PHCT quality, HOMECARE65 = Proportion of residents aged over 65 included in the home health care programme.

Table 1 describes the variables used and the role they play in the analysis. Summary statistics are shown in Table 2.

\section{[ Table 1 ]}

\section{[ Table 2 ]}

\subsubsection{Variables in the inefficiency effects model (environmental and control variables).-} In our model, unexplained systematic cost differences are attributed to inefficiency. However, the residual cost differences may also include factors related to output dimensions that are not accurately captured by the measures employed, and the resulting differences in cost cannot be regarded as efficiency differences in the usual sense. Taking this fact into account, we define two types of explanatory factors for the inefficiency effects model: environmental variables and control variables. Environmental variables are designed to test the sources of inefficiency.

Control variables are introduced into the model in order to test, given the limitations of the available information, for potential biased results induced by the use of proxy variables employed as output measures in our empirical approach. We define two control variables according to the available information: the proportion of residents aged over 64 (AGE65), and the number of months since the PHCT began to operate. AGE65 is introduced into the inefficiency effects model in order to test the influence of patient heterogeneity, which is not well captured in the cost function on the inefficiency level. The second variable, PCTAGE, is intended to test whether the number of years that have passed since the PHCT began to operate contributes towards explaining differences in quantity and quality of output and in purchasing cost, given PHCT heterogeneity with respect to this variable. It could be of interest to test the influence of the variable PCTAGE on the model if programme coverage is strongly determined by the number of years since the PHCT began to operate. 
Several types of factors may explain inefficiency variation. First, we consider the size of the population as a proxy for the existence of scale economies. Second, we analyse the influence of certain geographical characteristics of the ABS which may influence provider costs (population density, urban or rural area), and also access costs for the patients (distance to the health centre). Our model also includes the possible influence of socio-economic characteristics of the population served (income and deprivation) on the inefficiency level. Given the observed retrospective base of a large part of the reimbursement considered in the contracts, we attempt to measure the influence of allocative inefficiency in production, using the ratio of nurses to doctors in each PHCT as a proxy value. Finally, the model is designed to test for the influence of the type of contract, distinguishing between the programme-contracts with the previous single integrated provider (the ICS) and the new contracts with private non-profit providers. According to this scheme, we define 9 environmental variables that may potentially explain the level of cost inefficiency:

- density of population in the ABS (DENS),

- dummy variable indicating that a PHCT is contracted outside the ICS group, that is, has a new contract (CONTRACT),

- average income level of the population (INCOME),

- average distance of the resident population to the primary health centre (DISTANCE),

- $\quad$ an index of deprivation (DEPRIV),

- ratio of nurses to doctors (NURSES/DOCTORS),

- total population covered (SIZE),

- dummy variable indicating that a PHCT is located in a rural area (RURAL), and

- dummy variable indicating that a PHCT is located in an urban area (URBAN).

Then, the empirical specification of the inefficiency effects model is the following:

$$
\begin{aligned}
& \mathrm{U}_{\mathrm{i}} ?=? \mathrm{~N}\left[?_{0}+?_{1} \mathrm{DENS}_{\mathrm{i}}+?_{2} \mathrm{CONTRACT}_{\mathrm{i}}+?_{3} \mathrm{INCOME}_{\mathrm{i}}+?_{4} \text { DISTANCE }_{\mathrm{i}}+?_{5}\right. \\
& \text { DEPRIV }_{i}+?_{6} \text { NURSES/DOCTORS }_{i}+?_{7} \text { SIZE }_{\mathrm{i}}+?_{8} \text { RURAL }_{\mathrm{i}}+?_{9} \mathrm{URBAN}_{\mathrm{i}}+ \\
& \left.?_{10} \mathrm{AGE}_{\mathrm{i}}+?{ }_{11} \mathrm{PCTAGE}_{\mathrm{i}}\right]
\end{aligned}
$$




\subsubsection{Comparison of publicly managed PHCT's and private non-profit PHCT's.- In the}

inefficiency effects model we introduced a variable to test whether new contracts with private non-profit providers (explicitly contracted out) were more or less efficient than those with the publicly managed PHCT's, belonging to the previous public monopoly integrating financing and provision. In Table 3 we present a comparison of variables between the two groups of PHCT's. Only 17 of the 180 PHCT's considered in this study are not publicly managed. Total purchasing cost per capita and pharmaceutical expenditure per capita are slightly higher in publicly managed PHCT's, but the difference has no statistical significance. Productivity ratios using activity measures, such as the number of visits, indicate that PHCT's under new organisational forms present a significantly higher number of visits per doctor, although the number of visits per nurse is slightly lower in these providers. Population areas served by the new contracted providers outside the ICS correspond to ABS's with an average income higher than that of those served by publicly managed providers. Finally, our data indicates that new contracted providers began to operate more recently than those belonging to the majority public provider group (ICS).

[ Table 3 ]

\section{Results}

\subsection{Estimates of the cost function}

Following Battese and Coelli [6], maximum likelihood estimation (performed using FRONTIER 4.1) was employed to simultaneously estimate the parameters of the stochastic cost frontier and the technical inefficiency effects model. The program automatically checks the OLS residuals for correct skewness before proceeding to a maximum likelihood estimate of the frontier. The results of this procedure, corresponding to the Cobb-Douglas cost function, are presented in Table 4 . The variance parameters are expressed in terms of ? $? ?^{2} \mathrm{U} /\left(?{ }^{2} \mathrm{U}+?^{2} \mathrm{~V}\right)$. 
A number of statistical tests were carried out to identify the appropriate functional forms and the presence of inefficiency and its trend. As a misspecification analysis we used loglikelihood ratio tests (LR) [14]. The test at a 5\% level of significance suggests that the Cobb-Douglas specification cannot be rejected against the Translog, and hence all results presented here refer solely to the Cobb-Douglas cost function.

Given that corrected $\mathrm{R}^{2}$ is $89.9 \%$ for OLS estimation of the purchasing cost function, $10.1 \%$ of the cost differentials remains unexplained. Several LR tests were performed to test various null hypotheses in the Cobb-Douglas function, as listed in Table 5. The first test shows that the null hypothesis that the coefficients associated with population coverage are zero is rejected. This result implies that purchasing cost is not only related to activity (number of professional visits) but also depends on the size of the population covered (independently of the frequency of their primary care visits), and even more importantly, purchasing cost is strongly influenced by the age mix of the covered population. The null hypothesis explored in test 2 is that each purchasing contract is located on the cost efficient frontier and that the systematic and random cost inefficiency effects are zero. The null hypothesis that ? is zero is rejected, suggesting that inefficiency was present in purchasing and that the average purchasing cost function is not an appropriate representation of the data. This means that the one-sided error component is highly significant and that residual cost differentials cannot be entirely attributed to statistical noise. Finally, tests 3 and 4 consider the null hypothesis that the inefficiency effects are not a function of the explanatory variables. Again, the null hypothesis is rejected, confirming that the joint effect of these variables on cost inefficiency is statistically significant.

[ Table 5 ?

The estimate ? indicates that the proportion of the one-sided error component in the total variance of the composed error term is as high as $86 \%$. Thus, purchasing cost inefficiencies are the dominant source of random errors. 
In the Cobb-Douglas purchasing cost function estimated in Table 4, parameters represent cost elasticities on the best-practice purchasing cost frontier. A high degree of multicollinearity was observed in the Cobb-Douglas stochastic frontier using the condition index. When the objective is to estimate cost elasticities, the parameter estimates of our frontier function are too unreliable because of the use of functional form specification and the attendant multicollinearity. Notwithstanding, multicollinearity is not necessarily a severe problem given that the aim of this paper is to focus on efficiency estimation.

Given the specifications of the Cobb-Douglas stochastic frontier model, the average purchasing cost efficiencies of primary care contracts in the 180 observed population areas in Catalonia in 1996 are presented in Table 6. The measure of cost efficiency is the ratio of minimum cost to observed cost. The value of purchasing cost efficiency ranges from zero to unity.

\section{[ Table 6]}

The mean purchasing cost efficiency of the 180 contracts is estimated to be 0.9200 . That is, in 1996 the average primary care contract was purchasing health services at a cost that could be reduced to $92 \%$ of its observed level without affecting the level of output. In other words, average contracts were $8.7 \%$ aboveabove the cost frontier. In Table 6 we present average inefficiency scores for the two groups of PHCT contracts. Average inefficiency for the contracts with the 163 publicly managed PHCT's is 0.9286 , i.e., the average contract is $92.9 \%$ below the cost frontier. However, average inefficiency scores are lower for the contracts with the 17 PHCT's contracted outside the previous integrated public monopoly: average inefficiency is 0.8376 , which means that the average contract in this group is $83.8 \%$ below the cost frontier. Nevertheless, differences between the two groups are not statistically significant.

We also analysed correlation coefficients of traditional partial indicators of efficiency with the purchasing cost efficiencies obtained in this paper. The partial ratios considered here are total expenditure per person, pharmaceutical expenditure per person, expenditure on derived services per person, and number of visits per doctor. These indicators should not be considered as explaining factors of inefficiency scores because they only partially measure the relationship between some inputs and outputs. 
[ Table 7 ]

All expenditure ratios per capita show significant correlation with purchasing cost inefficiency scores using the Pearson and also the Spearman correlation coefficient. Correlation coefficients are higher in the case of pharmaceutical expenditure than in the case of total or derived expenditures. The coefficients obtained indicate that inefficiency in purchasing primary care is strongly influenced by clinical decisions related to pharmaceutical prescription. The number of visits per doctor is not correlated with cost inefficiency when using the Pearson correlation coefficient.

\subsection{Estimates of the inefficiency function.}

Given the differences in levels of cost efficiency between purchasing contracts, it is appropriate to ask why some contracts achieve a relatively high efficiency score whilst others are less cost efficient. The inefficiency function provides some explanations for variation in efficiency levels between primary care contracts in Catalonia in 1996. It should be noted that since the variable explained by the inefficiency function is the mode of inefficiency, a positive sign on a parameter in Table 4 indicates that the associated variable has a negative effect on efficiency and a negative sign indicates a positive efficiency effect. Thus, according to the results presented in Table 4, primary care contracts with PHCT's outside the previous public monopoly group (CONTRACT) and with PHCT's with a larger number of nurses per doctor (NURSES/DOCTOR) and with a larger number of covered residents (SIZE) tend to be less efficient. However, contracts with PHCT's in urban areas tend to be more efficient. Poorly captured effects such as the age mix of the population (AGE65, PCTAGE) have not influenced inefficiency scores in the model since the PHCT began to operate.

According to the results of the inefficiency effects model presented in Table 4, three main conclusions can be drawn.

First, purchasing contracts are more cost efficient in the case of PHCT's located in urban areas, even accounting for size, population density and the average distance of the residents to the primary health centre. This result indicates that the same output level is 
purchased with a higher cost when contracting services for rural areas. However, when list size increases, which is more likely to happen in urban areas, a seemingly unjustified diseconomy of scale appears, as purchasing cost increases. It is not at all clear what this "urban effect" indicates. It could be interpreted as meaning that, given the importance of the retrospective base in the reimbursing system, urban PHCT's are more cost conscious and better managed. The increase in inefficiency associated with the list size of the population served by a PHCT indicates an unjustified higher purchasing cost per unit of output when the PHCT serves a more highly populated area. One hypothesis to be tested is that this behaviour is related to an increase in the number and price of pharmaceutical prescriptions when PHCT's attend a larger population (a "prescription effect").

Second, and contrary to expectations, the parameter associated with the ratio of nurses per doctor shows that the purchasing cost in those PHCT's with a higher ratio of nurses is not, in fact, more efficient. The shortage in the number of nurses per doctor has been taken as an indication of allocative inefficiency in the production of health care services in Spain. However, our results present evidence that the increased number of nurses in relation to doctors may not be used efficiently. Possibly, this result could be attributed to the fact that nurses' time is not used as a substitute for doctors' time. Instead, nurses' time would be devoted to their own activities (diet counselling, obesity control, etc.), which are either not very efficient or are not well captured in our model.

The third observation relates to the type of purchasing contract. The efficiency level of a purchasing contract seems to be negatively associated with contracts with PHCT's that feature new organisational forms and are not publicly managed. As compared with contracts with publicly managed PHCT's (those belonging to the ICS), contracts with new providers outside the ICS represent a higher cost to the purchaser for the same level of output. This appears to be contrary to what would be predicted by economic theory regarding the process of separation between the purchaser and provider functions (purchaser-provider split) and the fostering of provider competition. This "contract effect" could be interpreted as the result of the low or null degree of risk transfer to the new providers and the fact that pharmaceutical costs are excluded from the contract. The evidence from our sample does not support the premise that contracting out has helped to improve purchasing cost efficiency in primary care. 
However, further considerations need to be taken into account for a more accurate evaluation and interpretation of the implications of the results as regards the type of PHCT contract. First, in 1996 and still today, the number of providers outside the previous integrated public monopoly is small, and provider competition is probably still a thing of the future. Furthermore, policy implications are different depending on whether differential cost inefficiency in contracted-out PHCT's is related to services reimbursed under the explicit contract between purchaser and provider, or whether it is related to services financed directly by the SCS but not included in the contract with the provider, such as pharmaceutical prescriptions.

When the number of alternative providers in the market is so small, the first objective of the purchaser is to offer incentives for the entrance of new providers into the primary care market. One efficient policy to offer incentives for market entrance and for the financial consolidation of those already in the market could be to give them a bonus above the justifiable cost of the services in the initial stages of the purchaser-provider split. If this purchasing "excess cost" declines in the following years, as the number of new entrants increases, this cost inefficiency could be interpreted as a transition cost to a more market oriented primary care sector. Improvement of performance in purchasing contracts can more than compensate for the "temporary excess costs". Notwithstanding, the same empirical effect may simply be interpreted as an example of purchaser capture by the new providers.

However, the possible interpretation suggested in the preceding paragraph for the "contract effect" would be misguided if cost inefficiency in contracted-out PHCT's were related to pharmaceutical costs. Purchasing cost, as described in the second section of this paper, is composed of two factors. The first is the direct payment of the purchaser to the provider. The second is the cost directly derived from the clinical decisions of this provider but not included in the contract, prescription costs being the most important of these. In order to gain acceptance for the "temporary excess cost" hypothesis, inefficient purchasing cost need only be observed in the first component of this purchasing cost. However, there are no observable incentives in the contracted-out PHCT's to minimise prescription costs in the present contracting system. 
A partial contrast of the so-called "prescription effect" and the "temporary excess cost" hypothesis is proposed as follows. A frontier cost function for the provision of pharmaceutical services to a population area is estimated for the 180 PHCT's in Catalonia in 1996 using the stochastic Battese and Coelli [6] model. The cost function for pharmaceutical services is based on the model of Bates et al [16]. Given that prices for pharmaceuticals are identical for all PHCT's, variables in the cost function are defined as the three groups of resident population classified according to their age (see Table 1). In the inefficiency effects model for pharmaceutical cost we consider the same variables as were tested in the purchasing cost function analysed above. Thus, the variables in the inefficiency effects model are those described in Table 1.

We can expect pharmaceutical cost efficiency to be positively associated with urban PHCT's and negatively related to more highly populated basic health areas as necessary conditions for the "prescription effect" hypothesis. Also, a necessary condition for the "temporary excess cost" hypothesis is that pharmaceutical cost inefficiency cannot be positively associated with the new contracted-out PHCT's. The results of simultaneously estimating the parameters of the stochastic pharmaceutical cost frontier and the cost inefficiency effects models are presented in Table 8 .

\section{[ Table 8 ]}

A generalised likelihood ratio test yields a statistic of 33.1, which has a ${ }^{2}$ distribution with eleven degrees of freedom under the null hypothesis of insignificant inefficiency effects. This means that the one-sided error is highly significant and that residual differentials cannot be entirely attributed to statistical noise.

The stochastic cost frontier for the pharmaceutical provision presents significant cost elasticities only for population aged over 14. Inefficiency scores in this model are highly correlated with pharmaceutical expenditure per person $(0.670$ Pearson coefficient) and with purchasing cost efficiency scores (0.656 Pearson coefficient). The average inefficiency score on the pharmaceutical cost frontier is 0.9087 . This score is slightly lower in contracted-out PHCT's (0.8812) than in publicly managed PHCT's (0.9115), but differences are not significant. 
The two hypotheses stated above cannot be discarded in view of the results of the inefficiency effects models for the pharmaceutical services provided by the 180 PHCT's in Table 8. PHCT's located in urban areas (URBAN), with a larger percentage of population aged over 64 (PCTAGE), and in more deprived areas (DEPRIV) tend to be more efficient in providing pharmaceutical services, although those PHCT's with a larger resident population (SIZE) tend to be more inefficient. That is, inefficiency in pharmaceutical provision is positively associated with list size, indicating that when the number of residents increases, prescription cost per person also increases, even when we account for certain indicators of patient heterogeneity. Another important feature of the results in Table 8 that supports the "temporary excess cost" hypothesis is the fact that the variable CONTRACT is not associated with inefficiency in pharmaceutical provision. However, this indicates that new contracted-out PHCT's are not more (but also not less) efficient in providing pharmaceutical services to their assigned population.

\section{Conclusions}

The principal objective of this paper is to provide new information on the effects of changes in primary care contracting in the Catalan health system. We have attempted to show the possibility of developing measures of cost efficiency that would be useful for the evaluation of public purchasing agencies in contracting health services from public and private providers. To our knowledge, this is the first study to present estimates of cost efficiency in contracting health services, to employ the approach developed by Battese and Coelli [6] in this context, and to explore the explanatory factors of inefficiency variations.

In our opinion, when evaluating whether it is "cheaper" to buy services by contract than to perform them in the public system, it is crucial to distinguish between cost efficiency in contracting health services from cost efficiency in producing health services. This distinction becomes even more important when not only not-for-profit but also forprofit provision is allowed, as is the case with primary health services in Catalonia, because it seems likely that any profit arising from private provision will accrue to the providers themselves [17]. 
The evidence from our sample of PHCT contracts does not support the premise that contracting out has helped improve cost efficiency. The mean purchasing cost efficiency of the 180 contracts is estimated to be 0.92 . The analysis reveals that the theoretical assumptions, positing higher efficiency levels for purchasing from contracted-out PHCT's, are unfounded: the average contract for publicly managed PHCT's is $7.6 \%$ above the cost frontier, while the average contract in the group of contracted-out PHCT's is 19,3\% above the cost frontier. On further investigation of the sources of cost inefficiency to see what characteristics are responsible for the variations in the efficiency level, we find that the efficiency level of a purchasing contract seems to be negatively associated with those contracts with PHCT's that feature new organisational forms and are not publicly managed. This excess cost does not affect the cost of pharmaceutical services provided by each PHCT.

Our results obtained with cross-section data allow efficiency level measures to be obtained for a given year (1996), together with factors explaining inefficiency variations between contracts in that year. The excess cost observed for contracted-out PHCT's could be attributed to an efficient policy designed to encourage market entry at the beginning of the purchaser-provider split. Alternatively, it may simply be attributable to purchaser inefficiency in the form, for example, of purchaser capture by a limited number of providers. Our cross-section data set does not allow testing between these competing or complementary explanatory hypotheses, which would require a panel data set and a larger number of contracted-out PHCT's.

However, given that the measures obtained here are relative, our results indicate that newly contracted providers are equally inefficient in pharmaceutical provision, which accounts for more than half of primary care costs, as publicly managed PHCT's. The new organisational forms employed with the contracted PHCT's do not effectively encourage cost effective prescribing, which would result in a lower cost per capita for a given level of need. This suggests that whether management is public or private, an increase in the purchaser-provider split has to be accompanied by proper definition of negotiated objectives (assigning weights to multi-objectives), and adequate levels of incentive and risk transfer to raise the cost efficiency of the contracts. If this is not the case, contract performance will be compromised and transaction costs raised. 


\section{Acknowledgements}

We are grateful to Tino Martí, Vicenç Grenzner and Daniel Serra, and two anonymous referees who generously provided helpful assistance and suggestions in preparing the data set used in this research. Financial support is acknowledged from the Ministerio de Ciencia y Tecnología under grant SEC2000-1187 and the Public Administration School of the Generalitat de Catalunya. 


\section{References}

1. López-Casasnovas G. Cost-Containment in Health Care: The Case of Spain from the Eighties up to 1997. Economics Working Paper 278, Department of Economics and Business, Universitat Pompeu Fabra: Barcelona, 1998.

2. Rodríguez M, Scheffler RM, Agnew JD. An Update on Spain's Health Care System: Is it Time for Managed Competition?. Health Policy 2000; 51: 109-131.

3. López G, Ortún V, Murillo C. El sistema sanitario español. Informe de una década. Fundación BBV Documenta: Bilbao, 1999.

4. Violan C. Nuevas formas de gestión en atención primaria. Nuevas propuestas de gestión, ¿por qué?. Medicina Clínica 1999; 24(3): 123-125.

5. Martí T, Grenzner V. Modelos de Atención Primaria en Catalunya. Cuadernos de Gestión en Atención Primaria 1999; 5(3): 116-129.

6. Battese GE, Coelli TJ. A Model for Technical Inefficiency Effects in a Stochastic Frontier Production Function for Panel Data. Empir Econ 1995; 20: 325-332.

7. Puig-Junoy J. Eficiencia en la atención primaria de salud: Una revisión crítica de las medidas de frontera. Rev Esp Salud Pública 2000; 74: 483-495.

8. Giuffrida A, Gravelle H. Measuring Performance in Primary Care: Econometric Analysis and DEA. Appl Econ 2001; 33: 163-176.

9. Primary Health Care Study Group-Barcelona. Induced prescription in primary health care. European Journal of General Practice 1999; 5: 49-53.

10. Jondrow J, Lovell CA, Materov I, Schmidt P. On the estimation of technical inefficiency in the stochastic frontier production function model. $J$ Econom 1982; 13: 233-238.

11. Battese GE, Coelli TJ. Prediction of farm-level technical efficiencies with a generalised frontier production function and panel data. J Econom 1988; 38: 387-399.

12. Salinas-Jiménez J, Smith P. Data envelopment analysis applied to quality in primary health care. Annals of Operations Research 1996; 67: 141-161.

13. Giuffrida A. Productivity and efficie ncy changes in primary care: a Malmquist index approach. Health Care Manag Sci 1999; 2: 11-26.

14. Kumbhakar SC, Hesmati A, Ljalmarsson L. Temporal patterns of technical efficiency: Results from competing models. International Journal of Industrial Organization 1997; 15: 597-616.

15. Kodde DA, Palm FC. Wald Criteria for jointly testing equality and inequality. Econometrica 1986; 54: 1243-1248. 
16. Bates JM, Baines B, Whynes RD. Measuring the efficiency of prescribing by General Practitioners. J Oper Res Soc 1996; 47: 1443-1451.

17. Evans RG, Barer ML, Lewis S, Rachlis M, Stoddart GL. Private Highway, OneWay Street: The Deklein and Fall of Canadian Medicare?. Discussion Paper 3D. Health Services \& Policy Research. University of British Columbia: Canada, 2000. 
Table 1. Description of the variables

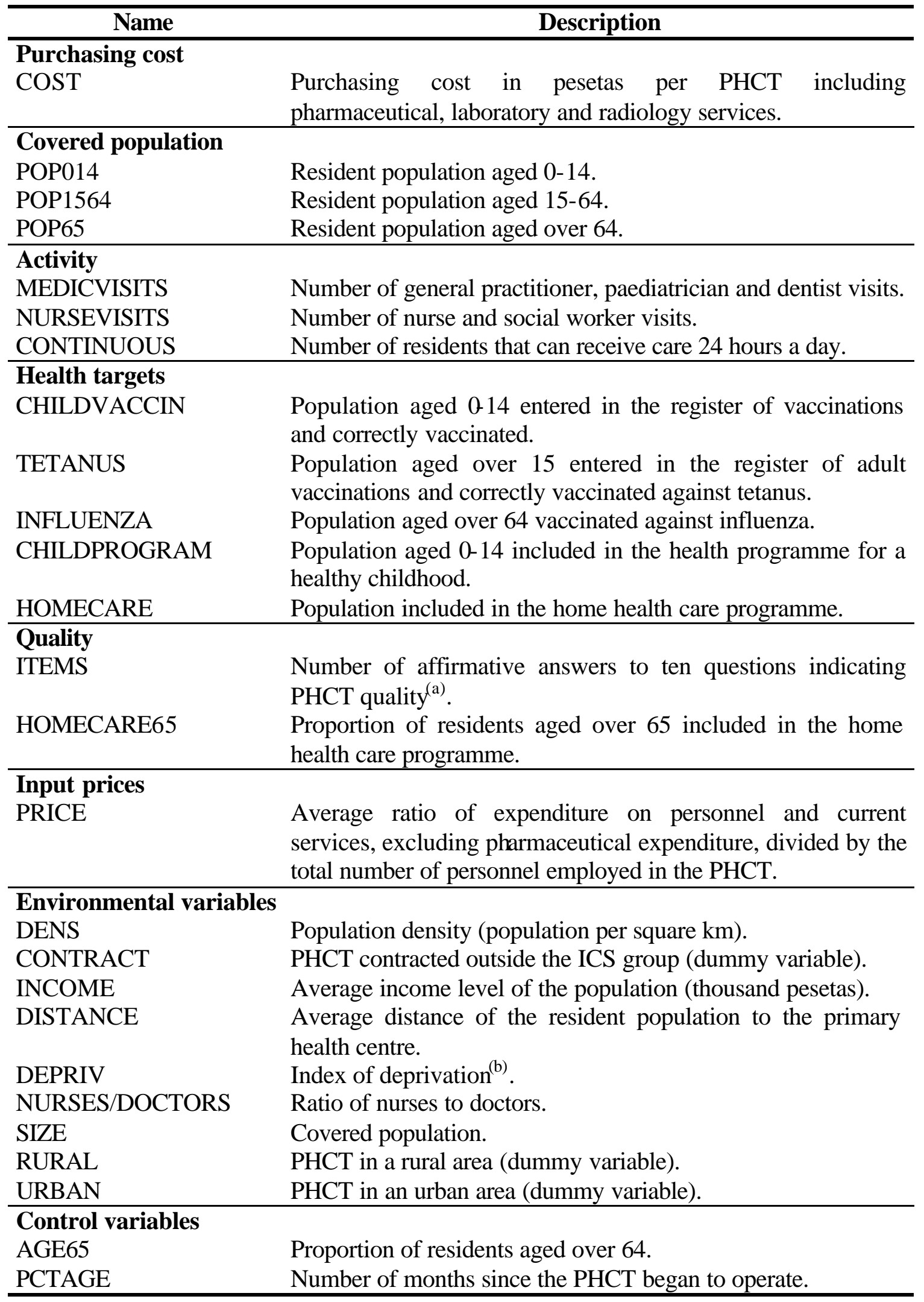

(a) The ten selected items are the following: a) Is there a regular paediatrics surgery in the afternoon after school finishes? b) Is there a telephone attention service for the population with assigned professionals? c) Is 
there a clinical record archive management service in all the centres? d) Is there a register of child vaccinations? e) Is there a register of adult vaccinations? f) Has the health programme for a healthy childhood been introduced? g) Has the home health care programme been introduced? h) Is there a co-ordination protocol with the specialised centres? i) Is there a system for identifying the population attended over the last year? j) Are there in use two or more clinical protocols of home care accorded by the PHCT?

(b) Index of deprivation used by the Health Department in the remuneration of doctors, which takes integer values from 1 to 4 . 
Table 2. Summary statistics for variables in the stochastic frontier models $(\mathbf{n}=\mathbf{1 8 0})$

\begin{tabular}{|c|c|c|c|c|}
\hline Variable & $\begin{array}{c}\text { Sample } \\
\text { mean }\end{array}$ & $\begin{array}{l}\text { Standard } \\
\text { deviation }\end{array}$ & Minimum & Maximum \\
\hline COST & 560736129 & 255981397 & 168442701 & $1.606 \mathrm{E}+09$ \\
\hline POP014 & 2934 & 1704 & 469 & 9352 \\
\hline POP1564 & 11286 & 6007 & 2008 & 31296 \\
\hline POP65 & 2317 & 1286 & 495 & 7511 \\
\hline MEDICVISITS & 71012 & 38334 & 6237 & 229065 \\
\hline NURSEVISITS & 44858 & 28833 & 6705 & 168751 \\
\hline CONTINUOUS & 7732 & 8798 & 0 & 33017 \\
\hline CHILDVACCIN & 1054 & 1267 & 0 & 6061 \\
\hline TETANUS & 1999 & 2355 & 0 & 11531 \\
\hline INFLUENZA & 1212 & 1075 & 0 & 6150 \\
\hline CHILDPROGRAM & 1657 & 1384 & 0 & 6171 \\
\hline HOMECARE & 120 & 117 & 0 & 809 \\
\hline ITEMS & 2.58 & 4.02 & 0.00 & 10.00 \\
\hline HOMECARE65 & 0.05 & 0.04 & 0.00 & 0.31 \\
\hline PRICE & 10343590 & 1919239 & 6609458 & 172231111 \\
\hline DENS & 4146 & 6816 & 4 & 23190 \\
\hline CONTRACT & 0.09 & 0.29 & 0.00 & 1.00 \\
\hline INCOME & 1130 & 180 & 118 & 1800 \\
\hline DISTANCE & 2.03 & 2.84 & 0.00 & 17.74 \\
\hline DEPRIV & 2.34 & 0.98 & 1.00 & 4.00 \\
\hline NURSES/DOCTORS & 0.87 & 0.12 & 0.36 & 1.14 \\
\hline SIZE & 16537 & 8537 & 3258 & 44956 \\
\hline RURAL & 0.38 & 0.49 & 0.00 & 1.00 \\
\hline URBAN & 0.45 & 0.50 & 0.00 & 1.00 \\
\hline AGE65 & 0.15 & 0.05 & 0.00 & 0.28 \\
\hline PCTAGE & 65.47 & 30.41 & 12.00 & 120.00 \\
\hline
\end{tabular}


Table 3. A comparison of some variables in publicly managed PHCT's (ICS) and contracted-out PHCT's

\begin{tabular}{lccc}
\hline \multicolumn{1}{c}{ Variable } & $\begin{array}{c}\text { Publicly } \\
\text { managed } \\
\text { PHCT's }\end{array}$ & $\begin{array}{c}\text { Contracted- } \\
\text { out PHCT's }\end{array}$ & All PHCT's \\
& 163 & 17 & 180 \\
Number of PHCT's & 36730 & 35662 & 36629 \\
Total expenditure per person & $(9643)$ & $(7242)$ & $(9431)$ \\
& 19089 & 17758 & 18964 \\
Pharmaceutical expenditure per person & $(5939)$ & $(4280)$ & $(5806)$ \\
& 0.52 & 0.50 & 0.52 \\
Proportion of pharmaceutical expenditure & $(0.07)$ & $(0.08)$ & $(0.07)$ \\
& 0.07 & 0.07 & 0.07 \\
Proportion of expenditure on derived & $(0.04)$ & $(0.04)$ & $(0.04)$ \\
services* & 6181 & 7140 & 6264 \\
Number of visits per doctor & $(1645)$ & $(738)$ & $(1854)$ \\
& 0.88 & 0.80 & 0.87 \\
Number of nurses per doctor & $(0.11)$ & $(0.11)$ & $(0.12)$ \\
& 0.15 & 0.14 & 0.15 \\
Proportion of residents aged over 64 & $(0.05)$ & $(0.04)$ & $(0.05)$ \\
& 2.34 & 2.29 & 2.34 \\
Index of deprivation & $(0.98)$ & $(0.99)$ & $(0.98)$ \\
Income per capita & 1119 & 1234 & 1130 \\
& $(172)$ & $(222)$ & $(180)$ \\
Time PHCT has been operating & 67.8 & 43.4 & 65.47 \\
& $(30.0)$ & $(26.3)$ & $(30.41)$ \\
& & & \\
\hline
\end{tabular}

Standard deviation in parentheses.

* Derived services include radiology, laboratory and visits in specialised health centres. 
Table 4. Maximum-likelihood estimates of parameters of the Cobb-Douglas stochastic frontier cost function

Dependent variable: total purchasing cost

\begin{tabular}{|c|c|c|c|c|}
\hline Variable & Parameter & Coefficient & Standard error & t-ratio \\
\hline \multicolumn{5}{|l|}{ Stochastic frontier model: } \\
\hline Constant & $?_{0}$ & 7.5754 & 1.0118 & $7.49^{* * *}$ \\
\hline PRICE & $?_{1}$ & 0.2575 & 0.0600 & $4.29^{* * * *}$ \\
\hline MEDICVISITS & $?_{2}$ & 0.1969 & 0.0369 & $5.32^{* * *}$ \\
\hline NURSEVISITS & $?_{3}$ & 0.0670 & 0.0242 & $2.77^{* * *}$ \\
\hline CONTINUOUS & $?$ & 0.0037 & 0.0033 & 1.12 \\
\hline POP014 & $\begin{array}{l}? 4 \\
? 5\end{array}$ & 0.1630 & 0.0704 & $2.30^{* *}$ \\
\hline POP1564 & 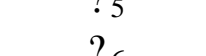 & 0.4546 & 0.0882 & $5.16^{* * *}$ \\
\hline POP65 & $? 6$ & 0.3148 & 0.0370 & $8.51^{* * *}$ \\
\hline CHILDVACCIN & $? 7$ & 0.0118 & 0.0038 & $3.09^{* * *}$ \\
\hline TETANUS & $? 8$ & 0.0040 & 0.0033 & 1.21 \\
\hline INFLUENZA & $? 9$ & -0.0016 & 0.0047 & -0.35 \\
\hline CHILDPROGRAM & $?_{10}$ & -0.0022 & 0.0042 & -0.52 \\
\hline HOMECARE & $? 11$ & 0.0125 & 0.0071 & $1.75^{*}$ \\
\hline ITEMS & $?_{12}$ & -0.0099 & 0.0137 & 0.72 \\
\hline \multirow[t]{2}{*}{ HOMECARE65 } & $?_{13}$ & 0.0228 & 0.0119 & $1.91^{*}$ \\
\hline & $? 14$ & & & \\
\hline \multicolumn{5}{|l|}{ Inefficiency effects model: } \\
\hline Constant & $?_{0}$ & -0.0235 & 0.9989 & $-2.35^{* * * *}$ \\
\hline DENS & $?_{1}$ & -0.0000 & 0.0000 & -1.61 \\
\hline CONTRACT & $?_{2}$ & 0.3983 & 0.1525 & $2.61^{* * * *}$ \\
\hline INCOME & $\dot{?}_{3}^{2}$ & 0.0003 & 0.0003 & 1.14 \\
\hline DISTANCE & $\dot{?}_{4}^{3}$ & -0.0633 & 0.0417 & -1.52 \\
\hline DEPRIV & $?_{5}^{4}$ & 0.0347 & 0.0555 & 0.62 \\
\hline NURSES/DOCTORS & $\cdot 5$ & 0.8243 & 0.3981 & $2.07^{* *}$ \\
\hline SIZE & $? 6$ & 0.0004 & 0.0001 & $2.48^{* *}$ \\
\hline RURAL & $? 7$ & 0.1975 & 0.1566 & 1.26 \\
\hline URBAN & $?_{8}$ & -0.5442 & 0.2254 & $-2.42^{* *}$ \\
\hline AGE65 & $? 9$ & 2.2915 & 1.6320 & 1.40 \\
\hline PCTAGE & $?_{10}$ & -0.0028 & 0.0020 & -1.44 \\
\hline & $?_{11}$ & & & \\
\hline \multicolumn{5}{|l|}{ Variance parameters: } \\
\hline & $?^{2} \mathrm{~s}$ & 0.0751 & 0.0199 & 3.78 \\
\hline \multirow[b]{2}{*}{ Log-likelihood function } & $?$ & 0.8586 & 0.0448 & 19.17 \\
\hline & & 113.39 & & \\
\hline
\end{tabular}

Notes:

1. The t-ratios are asymptotic t-ratios.

2. $* * * \mathrm{p}<0.001 ; * * \mathrm{p}<0.05 ; * \mathrm{p}<0.01$ 
Table 5. Generalised likelihood ratio tests of hypotheses for parameters of the stochastic frontier cost function

\section{Test Null hypothesis $\left(H_{0}\right) \quad$ Log-likelihood Value of? Critical value Decision (at} $5 \%$ level)

\begin{tabular}{llcccc} 
& $\mathrm{H}_{1}$ (Cobb-Douglas) & 113.39 & & & \\
1 & $\mathrm{H}_{0}: ?_{5}=?_{6}=?_{7}=0$ & 65.91 & 94.96 & 7.05 & Reject $\mathrm{H}_{0}$ \\
2 & $\mathrm{H}_{0}: ?=?_{0}=\ldots . .=?_{11}=0$ & 95.32 & 36.14 & 21.74 & Reject $\mathrm{H}_{0}$ \\
3 & $\mathrm{H}_{0}: ?_{1}=\ldots . .=?_{11}=0$ & 98.65 & 29.48 & 19.05 & Reject $\mathrm{H}_{0}$ \\
4 & $\mathrm{H}_{0}: ?_{0}=0$ & 111.71 & 3.36 & 2.71 & Reject $\mathrm{H}_{0}$ \\
\hline
\end{tabular}

Notes: ? : likelihood ratio test statistic, ? $=-2\left\{\log \left[\operatorname{Likelihood}\left(\mathrm{H}_{0}\right)\right.\right.$ ? $-\log \left[\operatorname{Likelihood}\left(\mathrm{H}_{1}\right)\right.$ ? . It has an approximate chi-square distribution with degrees of freedom equal to the number of independent constraints. The asymptotic distribution of hypothesis tests involving a zero restriction on the parameter ? has a mixed chi-squared distribution; therefore, the critical value for this test is taken from Kodde and Palm (1986), Table 1, page 1246. 
Table 6. Mean efficiency values by type of contract

\begin{tabular}{lcccc}
\hline \multicolumn{1}{c}{ Type of contract } & Mean & $\begin{array}{c}\text { Standard } \\
\text { deviation }\end{array}$ & Minimum & Maximum \\
\hline All PHCT's (n=180) & 0.9200 & 0.0758 & 0.4363 & 0.9797 \\
Publicly managed PHCT's (n=163) & 0.9286 & 0.0549 & 0.4363 & 0.9797 \\
Contracted-out PHCT's (n=17) & 0.8376 & 0.1605 & 0.4734 & 0.9689 \\
& & & & \\
\hline
\end{tabular}

Table 7. Correlation of inefficiency scores with some cost and productivity ratios

\begin{tabular}{lcc}
\hline \multicolumn{1}{c}{ Ratio } & $\begin{array}{c}\text { Pearson correlation } \\
\text { coefficient }\end{array}$ & $\begin{array}{c}\text { Spearman correlation } \\
\text { coefficient }\end{array}$ \\
\hline Total expenditure per person & $0.2464^{* *}$ & $0.3147^{* *}$ \\
Pharmaceutical expenditure per person & $0.4841^{* *}$ & $0.4652^{* *}$ \\
$\begin{array}{l}\text { Expenditure on derived services per } \\
\text { person }\end{array}$ & $-0.2657^{* *}$ & $-0.2150^{* *}$ \\
Visits per doctor & -0.0899 & $-0.2539^{* *}$ \\
\hline
\end{tabular}

$\mathrm{n}=180$.

$* * \mathrm{p}<0.05$. 
Table 8. Maximum likelihood estimates of parameters of the Cobb-Douglas stochastic cost frontier for the production of pharmaceutical services

Dependent variable: pharmaceutical expenditure

\begin{tabular}{lcccc}
\hline \multicolumn{1}{c}{ Variable } & Parameter & Coefficient & $\begin{array}{c}\text { Standard } \\
\text { error }\end{array}$ & t-ratio \\
\hline Stochastic frontier model: & & & & \\
\hline Constant & $?_{0}$ & 11.8024 & 0.3655 & $32.29^{* * *}$ \\
POP014 & $?_{1}$ & 0.0599 & 0.1091 & 0.55 \\
POP1564 & $?_{2}$ & 0.4552 & 0.1237 & $3.68^{* * *}$ \\
POP65 & $?_{3}$ & 0.3734 & 0.0570 & $6.55^{* * *}$ \\
& & & & \\
Inefficiency effects model: & & & & \\
Constant & $?_{0}$ & 0.6482 & 0.5255 & 1.23 \\
DENS & $?_{1}$ & -0.0001 & 0.0001 & -0.77 \\
CONTRACT & $?_{2}$ & -0.1020 & 0.1159 & -0.88 \\
INCOME & $?_{3}$ & -0.0003 & 0.0002 & -0.14 \\
DISTANCE & $?_{4}$ & -0.0218 & 0.0200 & -1.09 \\
DEPRIV & $?_{5}$ & -0.1275 & 0.0674 & $-1.89^{*}$ \\
NURSES/DOCTORS & $?_{6}$ & 0.0002 & 0.3598 & -0.68 \\
SIZE & $?_{7}$ & 0.0873 & 0.0000 & $2.88^{* * * *}$ \\
RURAL & $?_{8}$ & -0.6301 & 0.2514 & $-2.51^{* * *}$ \\
URBAN & $?_{9}$ & -0.8949 & 0.9569 & -0.93 \\
AGE65 & $?_{10}$ & -0.0045 & 0.0024 & $-1.86^{*}$ \\
PCTAGE & $?_{11}$ & & & \\
Variance parameters: & & & & \\
& $?^{2}{ }_{\mathrm{S}}$ & 0.0605 & 0.0192 & 3.15 \\
Log-likelihood function & $?^{*}$ & 0.4017 & 0.2372 & 1.69 \\
& & 33.1 & & \\
\hline
\end{tabular}

Notes:

1. The $\mathrm{t}$-ratios are asymptotic $\mathrm{t}$-ratios.

2. $* * * \mathrm{p}<0.001 ; * * \mathrm{p}<0.05 ; * \mathrm{p}<0.01$. 